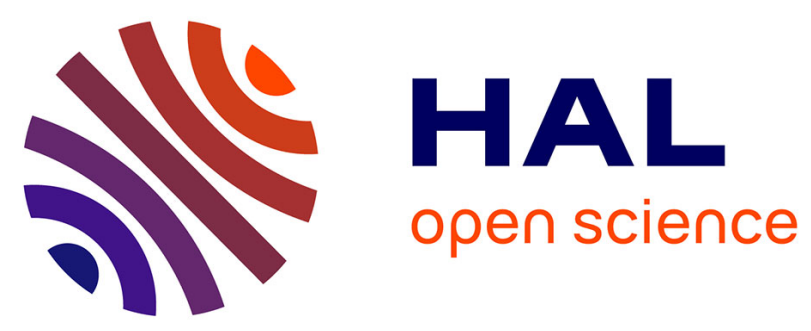

\title{
Redox active Double Wall Carbon Nanotubes show intrinsic anti-proliferative effects and modulate autophagy in cancer cells
}

Silvana Fiorito, Emmanuel Flahaut, Stefania Rapino, Francesco Paolucci, Federica Andreola, Noemi Moroni, Eugenia Pittaluga, Manuela Zonfrillo, Giovanni Valenti, Arianna Mastrofrancesco, et al.

\section{To cite this version:}

Silvana Fiorito, Emmanuel Flahaut, Stefania Rapino, Francesco Paolucci, Federica Andreola, et al.. Redox active Double Wall Carbon Nanotubes show intrinsic anti-proliferative effects and modulate autophagy in cancer cells. Carbon, 2014, vol. 78, pp. 589-600. 10.1016/j.carbon.2014.07.046 . hal01465877

\section{HAL Id: hal-01465877 https://hal.science/hal-01465877}

Submitted on 13 Feb 2017

HAL is a multi-disciplinary open access archive for the deposit and dissemination of scientific research documents, whether they are published or not. The documents may come from teaching and research institutions in France or abroad, or from public or private research centers.
L'archive ouverte pluridisciplinaire HAL, est destinée au dépôt et à la diffusion de documents scientifiques de niveau recherche, publiés ou non, émanant des établissements d'enseignement et de recherche français ou étrangers, des laboratoires publics ou privés. 


\section{OATAO \\ Open Archive Toulouse Archive Ouverte}

\section{Open Archive TOULOUSE Archive Ouverte (OATAO)}

OATAO is an open access repository that collects the work of Toulouse researchers and makes it freely available over the web where possible.

This is an author-deposited version published in : http://oatao.univ-toulouse.fr/ Eprints ID : 16579

To link to this article : DOI:10.1016/j.carbon.2014.07.046

URL : http://dx.doi.org/10.1016/j.carbon.2014.07.046

To cite this version : Fiorito, Silvana and Flahaut, Emmanuel and Rapino, Stefania and Paolucci, Francesco and Andreola, Federica and Moroni, Noemi and Pittaluga, Eugenia and Zonfrillo, Manuela and Valenti, Giovanni and Mastrofrancesco, Arianna and Groppi, Flavia and Sabbioni, Enrico and Bakalis, Evangelos and Zerbetto, Francesco and Serafino, Annalucia Redox active Double Wall Carbon Nanotubes show intrinsic anti-proliferative effects and modulate autophagy in cancer cells. (2014) Carbon, vol. 78. pp. 589-600. ISSN 0008-6223

Any correspondence concerning this service should be sent to the repository administrator: staff-oatao@listes-diff.inp-toulouse.fr 


\title{
Redox active Double Wall Carbon Nanotubes show intrinsic anti-proliferative effects and modulate autophagy in cancer cells
}

\author{
Silvana Fiorito ${ }^{a, d, *}$, Emmanuel Flahaut ${ }^{b}$, Stefania Rapino ${ }^{c}$, Francesco Paolucci ${ }^{c}$, \\ Federica Andreola ${ }^{d}$, Noemi Moroni ${ }^{d}$, Eugenia Pittaluga ${ }^{d}$, Manuela Zonfrillo ${ }^{d}$, \\ Giovanni Valenti ${ }^{c}$, Arianna Mastrofrancesco ${ }^{e}$, Flavia Groppi ${ }^{f}$, Enrico Sabbioni ${ }^{g}$, \\ Evangelos Bakalis ${ }^{c}$, Francesco Zerbetto ${ }^{c}$, Annalucia Serafino ${ }^{d}$ \\ a Dipartimento di Medicina Clinica, Università Sapienza, Roma, Italy \\ b Université Paul Sabatier-CNRS (CIRIMAT), Toulouse, France \\ c Dipartimento di Chimica "G. Ciamician", Università di Bologna, Bologna, Italy \\ d Institute of Translational Pharmacology, CNR, 00133 Roma, Italy \\ e San Gallicano Dermatologic Institute, IRCCS, Roma, Italy \\ ${ }^{\mathrm{f}}$ Università di Milano and INFN, Lab. Radiochimica-LASA, Segrate (Mi), Italy \\ ${ }^{g}$ Fondazione Università G. D’Annunzio-Ce.S.I., Chieti, Italy
}

\begin{abstract}
A B S T R A C T
In Double-Walled-Carbon-Nanotubes (DWCNTs) the outer shell screens the inner one from the external environment. As a consequence, the electronic properties of the smaller tube are enhanced and DWCNTs have therefore been advocated for a number of uses. In their raw form they may contain small metallic clusters, left over from the catalytic process, that can give them a redox activity characterized by redox potentials in the range of one hundred millivolts and able to affect biological systems. Indeed, we find that redox active raw-DWCNTs inhibit rat colorectal cancer cell proliferation by blocking cells in the G2 phase through ROS generation by tumor cells. We show that raw-DWCNTs could also modulate autophagy in tumor cells through induction of intracellular acidification. To the best of our knowledge, this is the first time that DWCNTs have been found to inhibit proliferation and modulate autophagy in cancer cells. Our work further supports previous studies that provided promising results on the possibility of future applications of Carbon Nanotubes (CNTs) in nanomedicine.
\end{abstract}

\section{Introduction}

The electrical properties of Carbon Nanotubes (CNTs) make them attractive for biomedical applications, especially when "electrically active" cells and/or tissues need to be interfaced with conductive nanomaterials in order to be stimulated for growth, proliferation and repair. Several studies, focusing on the capacity of these nanomaterials to interact with electrosensitive cells showed the potential of different CNT types as useful nano-tools exploitable in neuronal networks and

\footnotetext{
* Corresponding author at: Dipartimento di Medicina Clinica, Università Sapienza, Viale dell'Università 37, 00185 Roma, Italy.

E-mail address: silvana.fiorito@uniroma1.it (S. Fiorito). 
for the purpose of healing neurological and brain-related injuries [1-9].

Recently, also some cellular "charge-sensitive" parameters ( $\mathrm{pH}$, membrane polarity, organization of the cytoscheleton network) in cell types other than electro-sensitive neuronal cells, such as peripheral blood monocyte-derived macrophages and platelets, were shown to be affected by the contact with highly electro-conductive Multi-WalledCarbon-Nanotubes (MWCNTs) [10]. It was hypothesized that changes in cell membrane electrical properties triggered molecular signaling pathways leading to cell activation and inflammatory molecule secretion. Moreover, it was observed that highly electro-conductive MWCNTs modify calcium homeostasis in several cell types, providing evidence for a cationic exchange ability of MWCNTs due to the sorption of divalent ions on their surface [11].

Metallic impurities (Co, Mo, and Fe) can affect the electrochemical behavior of CNTs [12]. The presence of residual metal catalyst impurities could hinder the development of CNT-based biomedical applications [13] because of the proved toxicity of typical catalyst nanoparticles. However, the same metals could play a biologically important role at the interface between nanotubes and cell compartments. In fact, CNTs, due to the presence of electro-catalytic metals, possess the ability to mediate electron transfer with electro-active species in solution [14]. CNTs are able to promote the electrontransfer reactions of important biomolecules, including cytochrome c, NADH, catecholamine neurotransmitters, or ascorbic acid [15-18] together with a number of additional compounds, including halothane, amino acids, peptides, glucose, and hydrogen peroxide [19-21]. We investigated the effect of the impurities on the electrochemical and biological properties of CNTs, by analyzing cancer cell response to CNTs before and after purification.

\section{Experimental}

\subsection{Synthesis and characterization of carbon nanotubes}

Double-Walled Carbon Nanotubes (DWNTs) were synthesized by Catalytic Chemical Vapor Deposition (CCVD) as described earlier [22] and detailed in Supplementary Methods. The raw sample contained carbon-encapsulated ferromagnetic cobalt nanoparticles (Co@C) that were synthesized spontaneously during CCVD. For the sake of comparison and to prepare control samples, carbon-encapsulated Co nanoparticles (Co@C) were also prepared by CCVD, using different CCVD conditions, as described elsewhere [23] and detailed in Supplementary Methods. The so-obtained nanocomposite powder was then treated with a concentrated aqueous $\mathrm{HCl}$ solution to dissolve the unreacted catalyst as well as nonprotected metal nanoparticles, as in the case of CNTs. As reference material, purified DWCNTs and very pure pyrolytic graphite particles from graphitized carbon black (LCSM UMR7555 CNRSUHP Groupe MSC, Nancy, France) were used. Purified DWCNTs were prepared by heating in air at $500{ }^{\circ} \mathrm{C}$ for $30 \mathrm{~min}$. and followed by $\mathrm{HCl}$ washing. The samples were sterilized by heating at $180^{\circ} \mathrm{C}$, washed three times in distilled water, then suspended in Phosphate Buffered Saline (PBS) at a stock concentration of $1 \mathrm{mg} / \mathrm{ml}$. Dispersion was performed through a $12 \mathrm{~h}$ gently sonication, in a bath sonicator at the lowest power, and the particles were analyzed or put into the cell cultures for cell treatment immediately after sonication.

Full characterization of these CNTs was performed by Transmission Electron Microscopy (TEM), Raman Spectroscopy and Elemental analysis.

\subsection{Rat tumor cell line and in vitro treatments}

DHD/K12/Trb cell line, originally established from 1,2-dimethylhydrazine-induced colon adenocarcinoma in syngeneic BDIX rats, was obtained from the European Collection of Cell Culture (ECACC, Salisbury, UK), and maintained in culture as described in Supplementary Methods. For treatments, cells were seeded at a density of $6 \times 10^{4} / \mathrm{cm}^{2}$ and were maintained in culture for $24 \mathrm{~h}$ prior to treatments. Cells were treated with $30 \mu \mathrm{g} / \mathrm{ml}$ of raw-DWCNTs (or of pyrolytic graphite carbon particles for reference), a concentration selected as the lowest effective dose in preliminary dose-response experiments, and examined after $6 \mathrm{~h}$ and $24 \mathrm{~h}$ treatment. The effects of purified-DWCNTs and Co@C on DHD/K12/Trb cells have been analyzed at the same time points, using the concentrations of 30 and $60 \mu \mathrm{g} / \mathrm{ml}$. For microscopic analyses, cells were grown on cover-slips.

\subsection{Cell viability, cell proliferation and cell cycle analyses}

Cell viability was determined at $6 \mathrm{~h}$ and $24 \mathrm{~h}$ treatment, based on the Trypan blue exclusion method. Cell proliferation was assessed by evaluating the mitotic index (MI) and the percentage of cells exhibiting positivity for the proliferation marker Ki67, as detailed in Supplementary Methods. Quantitative assessment was done in a blinded fashion under a LEICA TCS SP5 Confocal Laser Scanning Microscopy (CLSM, Leica Instruments, Mannheim, Germany). A minimum of 500 cells/sample were counted and results were given as percentage of cells in mitosis.

The effects on the cell cycle were examined by cytofluorimetric analysis of DNA content after propidium iodide (PI) staining. Samples were analyzed using the flow cytometer FACS-Scan (Becton Dickinson). The block in the $G_{2}$ phase has been also evaluated after immunofluorescent staining of Ki67 that has been reported to localize at nucleolar level in the $G_{2}$ interphase [24]. The percentage of cells exhibiting nucleolar Ki67 positivity was obtained analyzing, in a blinded fashion, a minimum of 500 cells/sample by CLSM.

\subsection{Evaluation of apoptosis induction by TUNEL assay}

TUNEL assay for in situ apoptosis detection was performed by using the "In situ Cell Death Detection Kit" (Roche, Germany), according to the manufacturer's instructions. Details on the method and materials used are reported in Supplementary Methods. Cells treated with $4 \mu \mathrm{M}$ Staurosporine for $18 \mathrm{~h}$ were used as positive control of apoptosis induction. Samples was observed by CLSM. For the quantitative assessment analysis, a minimum of 500 nuclei/sample were counted in a blinded 
fashion and results were given as percentage of cells exhibiting nuclear TUNEL staining.

\subsection{Analysis of the intracellular $\mathrm{pH}$}

Intracellular $\mathrm{pH}$ changes were evaluated using the acidotropic probe LysoSensor Green DND-189 (Molecular Probes), as previously described [10], and detailed in Supplementary Methods. This probe, that freely passes through cell membranes and typically concentrates in acidic organelles exhibits a $\mathrm{pH}$-dependent increase or decrease in fluorescence intensity upon intracellular acidification or alkalinization, respectively. The changes in fluorescence intensity of LysoSensor probe were recorded by confocal microscopy in Live Data Mode acquisition, as detailed in Supplementary Methods. The quantitative analyses were performed using the Leica application suite for advanced fluorescence (LasAF) software (Leica Instruments).

\subsection{Immunocytochemical analysis}

Immunocytochemical analysis was carried out on cells fixed with $4 \%$ paraformaldehyde (Sigma-Aldrich) and permeabilized with $0.2 \%$ Triton X-100 (Sigma-Aldrich). Immunofluorescence staining was performed using the primary antibodies against Ki67, $\beta$-catenin, and E-cadherin, detailed in Supplementary Table 1. Primary antibodies were detected with Alexa Fluor 488-conjugated anti-mouse or anti-rabbit IgG (Molecular Probes). Cell nuclei were visualized by staining with $2 \mathrm{~g} / \mathrm{ml} \mathrm{PI}$ plus $0.1 \mathrm{mg} / \mathrm{ml}$ RNase (Sigma-Aldrich). Samples were observed by CLSM.

\subsection{Quantitative Reverse Transcription Polymerase Chain Reaction (QPCR)}

Transcription levels of E-cadherin, $\beta$-catenin, c-Myc and CyclinD1 genes were evaluated by QPCR in untreated controls and in cells treated with $30 \mu \mathrm{g} / \mathrm{ml}$ raw-DWCNTs or pyrolytic graphite carbon particles for reference, at times ranging from $1 \mathrm{~h}$ to $48 \mathrm{~h}$. Sequences of primers and details on the method used are reported in Supplementary Table 1 and in Supplementary Methods. Quantitative RT-PCR sample value was normalized for the expression of $\beta$-actin mRNA. The relative level for each gene was calculated using the $2^{-\Delta \Delta C t}$ method [25] and was reported in arbitrary units.

\subsection{Autophagy analysis by confocal microscopy}

Autophagy was evaluated by analyzing the redistribution at level of cytoplasmic vacuoles of the autophagy membrane marker LC3. Cells grown on cover-slips and treated with raw-DWCNTs for 6 h, $24 \mathrm{~h}$ and $48 \mathrm{~h}$, were subjected to immunofluorescent staining using the primary antibody against LC3, detailed in Supplementary Table 1. Cells grown in serum-free medium for $48 \mathrm{~h}$ (starvation condition), were used as positive control of autophagy. The percentage of LC3-positive cells ( $>3$ punctate staining sites per cell) as well as the number of LC3-stained vacuoles per positive cells was obtained analyzing in a blinded fashion a minimum of 200 cells/sample by CLSM.

\subsection{Western Blot (WB) analysis of LC3 expression and turnover}

For WB analysis, exponentially growing cells were seeded at a density of $6 \times 10^{4} / \mathrm{cm}^{2}$ and were maintained in culture for $24 \mathrm{~h}$ before treatments. For starvation conditions culture media was replaced with the same media without FBS. Cells were treated with raw-DWCNTs at a concentration of $30 \mu \mathrm{g} / \mathrm{ml}$ or subjected to starvation condition for 24 and $48 \mathrm{~h}$. Lysosomal turnover of endogenous LC3-II was analyzed in all samples (Control, DWCNTs and starvation) in absence and in presence of two lysosomal protease inhibitors, E64d (10 $\mu \mathrm{g} / \mathrm{ml})$ and Pepsatin A $(10 \mu \mathrm{g} / \mathrm{ml})$ (Applichem $\mathrm{GmbH}$, Germany). For total cell extracts, cells were washed with ice-cold PBS and lysed using RIPA buffer (20 mM Tris- $\mathrm{HCl} \mathrm{pH}$ of 7.4, $150 \mathrm{mM} \mathrm{NaCl}, 5 \mathrm{mM}$ $\mathrm{MgCl}_{2}, 0.1 \%$ SDS, $0.5 \%$ sodium deoxycholate, $1 \%$ Triton X100, $20 \mathrm{mM} \mathrm{NaF}, 1 \mathrm{mM}$ Na3OV4, $1 \mathrm{mM}$ PMSF and 2\% antiprotease cocktail (Sigma-Aldrich St. Louis, MO, USA). Protein concentrations were determined using Bradford reagent (Bio-Rad, Segrate, Italy); $30 \mu \mathrm{g}$ of each cell extract was separated by $12 \%$ SDS-PAGE and transferred to a PVDF membrane (Immobilon-P, Millipore, Billerica, MA, USA). Blots were incubated with rabbit monoclonal LC3B (Clone D11) (Cell Signaling Technology Boston, MA, USA; working dilution 1:1000; Cat.\# 3868) and with mouse monoclonal $\beta$-actin (Clone AC-15) (Sigma-Aldrich St. Louis, MO, USA, 1:9000; Cat.\# A5441) and then revealed with peroxidase-conjugated secondary antibodies (BioRad, Richmond, CA, USA). The ECL Detection System (Amersham, Uppsala, Sweden) was used for detection and Densitometric analysis was performed using the Image $\mathrm{J}$ processing program. Values were normalized to $\beta$-actin and were reported as relative amount of LC3-I and LC3-II (\% us untreated control). Data were presented as the mean \pm S.D.

\subsection{Fluorescent measurement of intracellular oxidative stress}

Intracellular ROS were determined with the probe 5-(and 6)carboxy-2',7'-dichlorodihydrofluorescein diacetate, acetyl ester (CM- $\mathrm{H}_{2}$ DCFDA) (Molecular Probes, Eugene, OR, USA). Following exposure to $30 \mu \mathrm{g}$ and $60 \mu \mathrm{g}$ of raw DWCNTs, Co@C particles and purified DWCNTs for $1 \mathrm{~h}$, cells were washed twice with PBS and incubated with $5 \mathrm{M} \mathrm{CM}-\mathrm{H}_{2}$ DCFDA in 154 medium without phenol red at $37{ }^{\circ} \mathrm{C}$ and $5 \% \mathrm{CO}_{2}$. Oxidative conversion of $\mathrm{CM}-\mathrm{H}_{2}$ DCFDA to the fluorescent product was assessed by flow cytometry using a FACSCalibur (Becton Dickinson, San José, CA, USA). The CELL-QUEST software was used for analyzing the data. The median fluorescence intensity of the probe, recorded for each sample, was used as the measure of the intracellular content of ROS because it matches the maximal number of cells with the highest fluorescence.

\subsection{Electrochemical instrumentation and measurements}

The electrochemical experiments were carried out in a polytetrafluoroethylene cell with a 6-mm-diameter aperture, and an O-ring was placed on top of the substrates and tightened using two connecting screws. The cell was also equipped with a platinum wire as counterelectrode and an $\mathrm{Ag} / \mathrm{AgCl}(3 \mathrm{M} \mathrm{KCl})$ 
reference electrode. CNT films were obtained by drop-casting $15 \mu \mathrm{L}$ of $1 \mathrm{mg} / \mathrm{mL}$ suspensions of CNTs in PBS buffer onto a conducting indium tin oxide (ITO)-coated glass substrate and by subsequent drying in air overnight. Cyclic voltammetry (CV) and electrochemical impedance spectroscopy (EIS) experiments (in the frequency range from $100 \mathrm{kHz}$ to $0.1 \mathrm{~Hz}$ ) were carried out with an Autolab model PGSTAT 30 (Eco Chemie, Utrecht, The Netherlands).

\subsection{Instrumental Neutron Activation Analysis (INAA)}

3.2-5.1 mg of raw DWCNTs, Co@C, purified DWCNTs and freeze-dried multielement standards solutions (Spectrosil solutions used for Atomic Absorption Spectroscopy) were sealed in polycarbonate vials and irradiated for $12 \mathrm{~h}$ in the Lazy Susan position of TRIGA MARK II Research Nuclear Reactor at LENA Laboratory of Università degli Studi di Pavia with a thermal neutron flux of $5 \times 10^{12}$ neutrons $\mathrm{cm}^{-2} \mathrm{~s}^{-1}$. After 3 days of decay the irradiated samples were submitted to high resolution computer-based gamma ray spectrometry using a HPGe detector to measure the produced radionuclides identified by their characteristic photon line emissions [26] ${ }^{60} \mathrm{Co}$ : 1173.8 and $1332.6 \mathrm{keV}$; ${ }^{59} \mathrm{Fe}: 1099.2$ and $1291.6 \mathrm{keV}$; ${ }^{99} \mathrm{Mo}$ : $140.5 \mathrm{keV}$ and ${ }^{69} \mathrm{Zn}: 438.6 \mathrm{keV}$. Release of cobalt from DWNTs into culture medium: the cobalt concentration, determined in milligram samples of DWNTs by INAA as previously reported was: $3.9 \pm 0.15 \%$ of the total mass by weight of nanotubes. Then, the radio-activated nanotube samples were used for the release studies as detailed in Supplementary Methods.

\subsection{Shift of potential of a dipole inside a conducting cylinder}

Three cases are considered in the solution of the Poisson equation with the Green function expansion method [27] as detailed in Supplementary Methods.

\subsection{Statistical analysis}

Statistical analysis was performed using the two-tailed Student's $t$ test and a $P$ value threshold of $<0.05$. All data were presented as mean $\pm \mathrm{SD}$.

\section{Results}

\subsection{Characterization of Double-Walled-Carbon-Nanotubes (DWCNTs)}

Based on our previous findings [10-11] we investigated whether another kind of nanotubes with metallic behavior [28], Double-Walled-Carbon-Nanotubes, could positively and selectively interact with tumor cells. We studied the biological effects of raw-DWCNTs synthesized by Catalytic Chemical Vapor Deposition (CCVD) [23] on rat colon adenocarcinoma cells. Full characterization of these CNTs was performed by Transmission Electron Microscopy (TEM), Raman Spectroscopy and Elemental analysis (Fig. 1). The elemental analysis (flash combustion) gave a carbon content of $89.4 \mathrm{wt} \%$. Raman spectroscopy ( $\lambda=488 \mathrm{~nm}$, not shown) gave a mean intensity ratio between the $D$ and $G$ bands ( 4 measurements at different places of the sample) of $5.5 \%$, which corresponds to very good structural quality. The raw sample contained carbon-encapsulated ferromagnetic cobalt nanoparticles (Co@C) that were synthesized spontaneously during CCVD. The nanoparticles, mainly ranging between 5 and $10 \mathrm{~nm}$, were tightly encapsulated by ordered carbon shells consisting of 2-3 graphene layers and protected from oxidation (Fig. 1). Earlier investigations showed that the Co is tightly encapsulated in the concentric graphene layers and does not get oxidized in air [29].

\subsection{Effects of raw-DWCNTs on viability, proliferation and cell cycle of rat adenocarcinoma cells}

The rat tumor DHD/K12/Trb cell line was challenged with $30 \mu \mathrm{g} / \mathrm{ml}$ of raw-DWCNTs (or of pyrolytic graphite particles as reference), a concentration selected as the lowest effective dose in preliminary dose-response experiments, and examined after $6 \mathrm{~h}$ and $24 \mathrm{~h}$. Cell viability, proliferation and cycle analyses were performed. Raw-DWCNTs induced a significant $(P=0.0022)$ reduction in the number of viable cells (Fig. 2a), and exerted an anti-proliferative effect on DHD/K12/Trb cells, as demonstrated by the reduction of mitotic index (Fig. 2b; significance: $P=0.0020$ ) and of the percentage of cells exhibiting nuclear positivity for Ki67 (Fig. 2c and Supplementary Fig. S1a; significance: $P=0.0062$ ), compared to controls.

The effects on the cell cycle, examined after $24 \mathrm{~h}$ of treatment by flow cytometry, showed that raw-DWCNTs blocked cells in $\mathrm{G}_{2} / \mathrm{M}$ phase (Fig. 2d). A higher percentage of cells blocked in G2/M phase in raw-DWCNT treated cultures, compared to the untreated controls, was also observed after the immunofluorescent staining of Ki67, that has been reported to localize at nucleolar level in the $\mathrm{G}_{2}$ interphase [24] (Supplementary Fig. S2).

\subsection{Assessment of apoptosis induction and influence on Wnt/ $\beta$-catenin signaling}

The assessment of apoptosis induction, evaluated by TUNEL assay after 6 and $24 \mathrm{~h}$ treatment, showed that apoptotic cells were almost absent in cultures challenged with raw-DWCNT, differently to that observed in cells treated with $4 \mu \mathrm{M}$ Staurosporine for $18 \mathrm{~h}$, used as positive control of apoptosis induction (Fig. 2e and Supplementary Fig. S1b). In order to understand the mechanism by which raw-DWNTs inhibit cancer cell proliferation, without inducing apoptosis, we analyzed if they affected the Wnt/ $\beta$-catenin signaling pathway, which deregulation or constitutive activation has a key role in the initiation and progression of different forms of human cancer [30]. The involvement of Wnt/ $\beta$-catenin pathway in the anti-proliferative effect of raw-DWCNTs had been preliminary suggested by the immunocytochemical analysis that showed a nuclear export of the oncoprotein $B$-catenin and an increased expression of E-cadherin at the cell-cell junctions, after the contact with raw-DWCNTs, (Fig. 3a).

To confirm these observation, the transcription levels of $\beta$ catenin gene and of the main target genes of the Wnt pathway, namely E-cadherin, $c-M y c$ and Cyclin- $D_{1}$ were evaluated by QPCR in cells treated with $30 \mathrm{~g} / \mathrm{ml}$ raw-DWCNTs, at times 

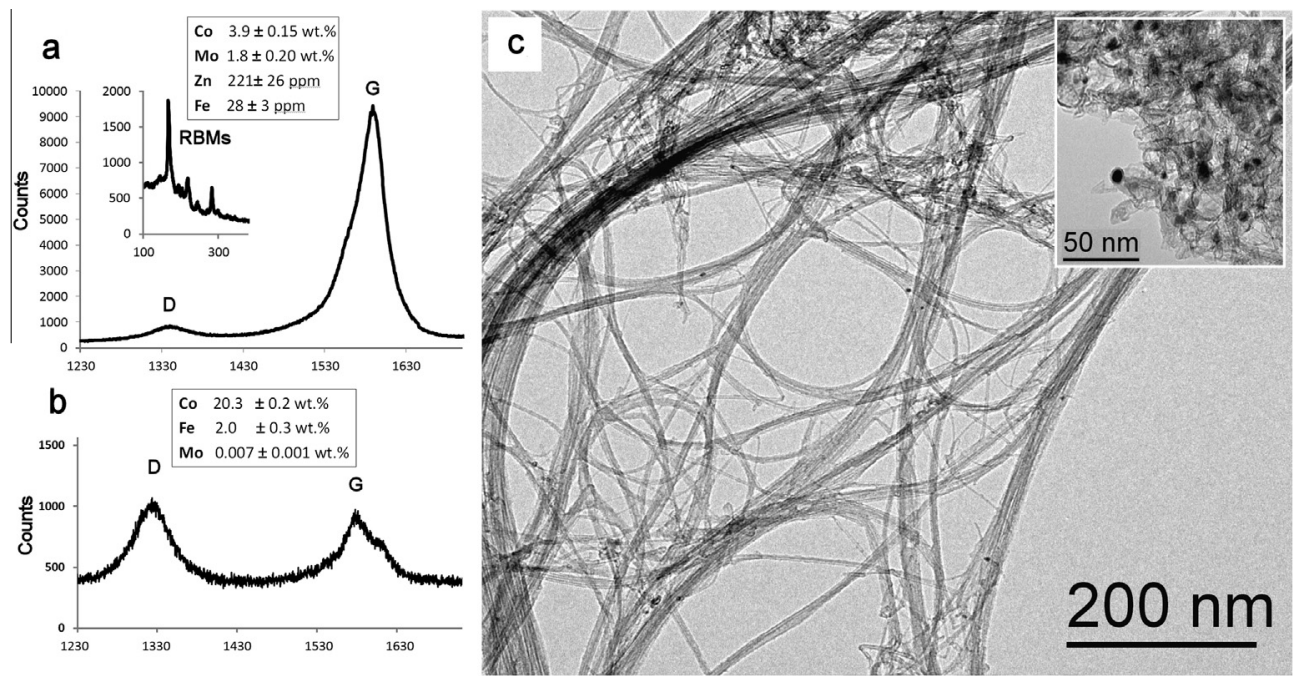

Fig. 1 - Characterization of raw-DWCNTs. Typical Raman spectra of (a) DWCNTs and (b) Co@C nanoparticles (boxes show the results of elemental analysis of each sample obtained by Instrumental Neutron Activation Analysis (INAA); (c) representative TEM image of DWCNTs, with an inset focusing on the Co@C by-product in these samples.
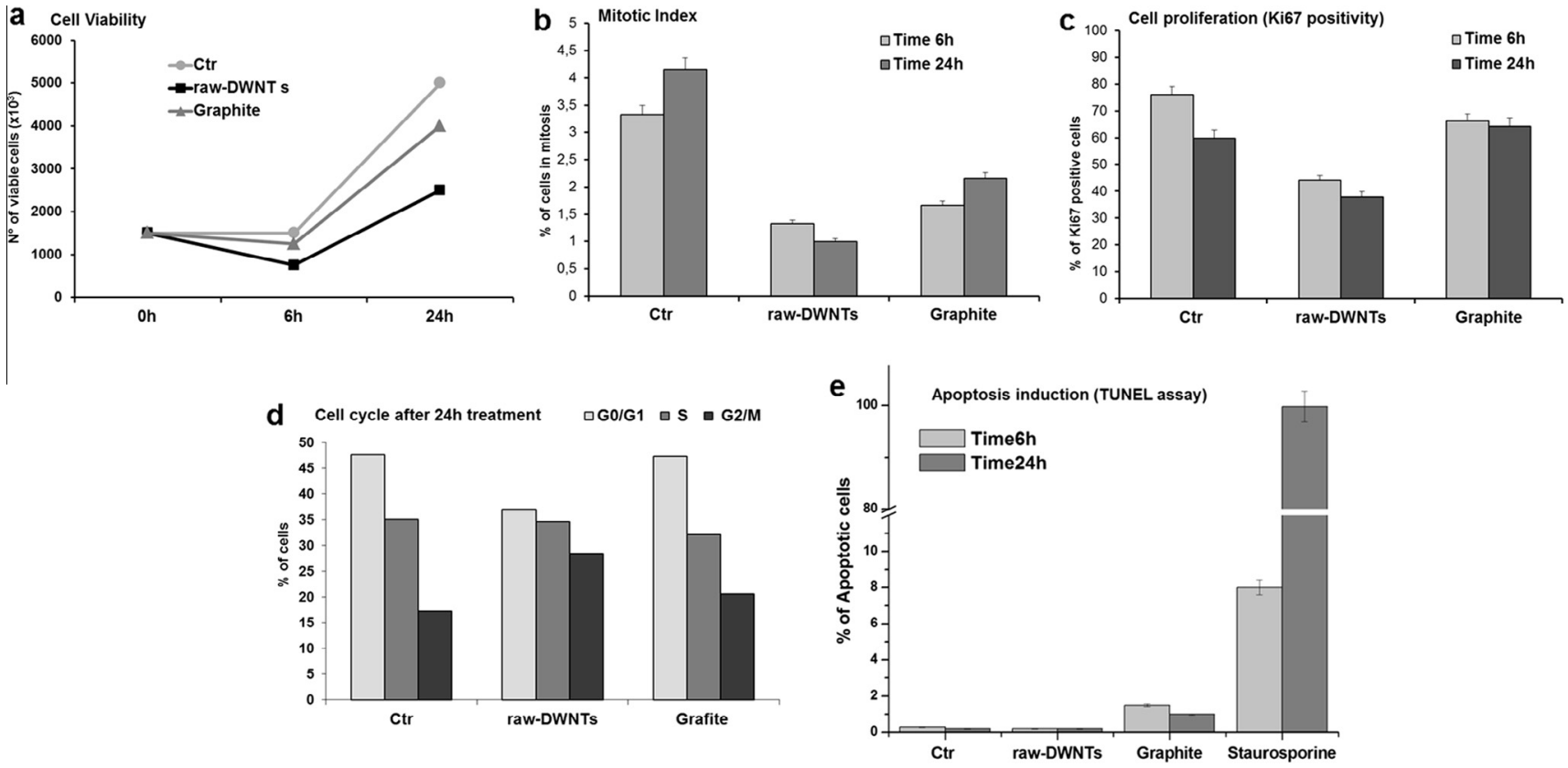

Fig. 2 - Effects of raw-DWCNTs on cell viability, proliferation, cycle and death in DHD/K12/trb cells. (a) Cell viability by Trypan blue exclusion method. (b) Mitotic index (MI) evaluation; results are given as percentage of cells in mitosis. (c) Cell proliferation evaluated by Ki67 immunofluorescent staining; results are given as percentage of cells exhibiting Ki67 positivity. (d) Cell cycle analysis by flow cytometry. (e) Apoptosis induction evaluated by TUNEL assay. Staurosporine was used as positive control of apoptosis induction; results are given as percentage of cells exhibiting nuclear TUNEL staining. For all assays, the quantitative assessment was done as described in the Methods section. Pyrolytic graphite particles were used as reference.

ranging from $1 \mathrm{~h}$ to $48 \mathrm{~h}$. Our findings, showing that raw-DWCNTs did not induce an early significant response of the expression of $\beta$-catenin, E-cadherin, c-Myc and Cyclin D1 genes (Fig. 3b) did not confirm the effect of raw-DWCNTs on $\mathrm{Wnt} / \beta$-catenin signaling.
3.4. Physical-chemical characterization of raw-DWCNTs and influence on intracellular $\mathrm{pH}$

The electrochemical behavior of raw-DWCNTs was evaluated by performing Cyclic Voltammetry (CV) on the raw-DWCNT 

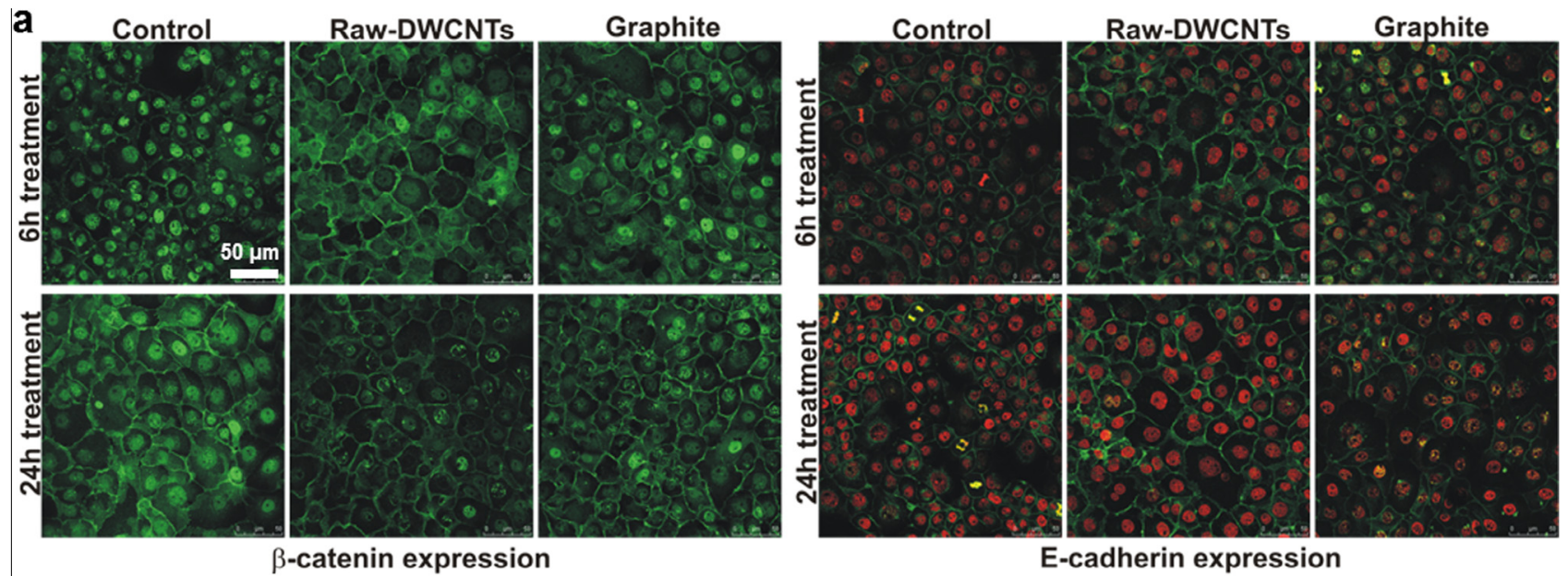

E-cadherin expression
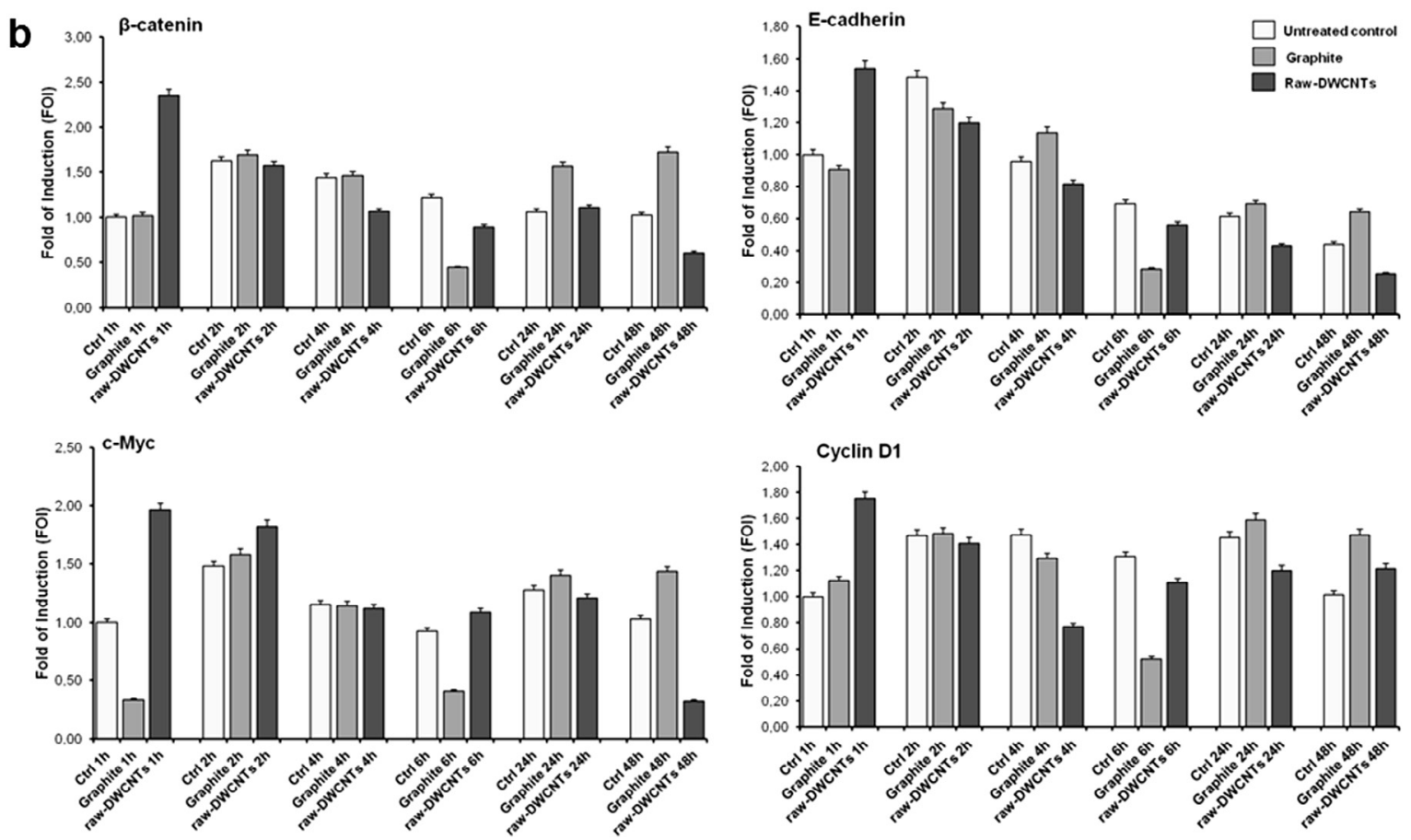

Fig. 3 - Effects of raw-DWCNTs on the intracellular distribution of $\beta$-catenin and E-cadherin and on the transcription of Wnt/ $\beta$ catenin pathway genes in DHD/K12/trb cells. (a) CLSM representative images of intracellular distribution of $\beta$-catenin and Ecadherin in control and raw-DWCNTs treated cells after $6 \mathrm{~h}$ and $24 \mathrm{~h}$ of culture; pyrolytic graphite particles were used as reference. Merged images of E-cadherin (green hue) with PI nuclear staining (red hue) are shown. (b) Real time PCR analyzing the transcription levels of $\beta$-catenin, E-cadherin, c-Myc, and Cyclin-D1 after 1, 2, 4, 6, 24 and $4 \mathrm{~h}$ of treatment. Results represent the mean of two independent experiments using independent cells culture in each experimental setting. (A color version of this figure can be viewed online.)

sample on ITO (conducting indium tin oxide-coated glass substrate). $\mathrm{CV}$ showed a redox peak, with $\mathrm{E}_{1 / 2}$ potential, at $\sim 70 \mathrm{mV}$, attributable to metallic impurities left over from the catalyst used in the synthesis (Fig. 4a). Instrumental Neutron Activation Analysis (INAA) showed that raw-DWCNTs contained Co $(\% 3.9 \pm 0.15)$, Mo $(\% 1.8 \pm 0.2)$, Zn (ppm $221 \pm 26$ ), Fe (ppm $28 \pm 3$ ) (Fig. 1a). The analysis of Co ion release from raw-DWCNTs into culture medium, using ${ }^{60} \mathrm{Co}$ (obtained by neutron activation) as tracer, showed limited release of Co into RPMI culture medium (\% of Co associated to raw-DWNTs was $1.1-1.3 \%$ of the initial content before sonication and $2.1 \%$ after sonication). Such release data are referred to the time $(24 \mathrm{~h})$ of cell treatment with DWCNTs. Since the release could be a time dependent reactioncontrolled oxidative dissolution we cannot exclude that they may vary over time in different experiments. Thus, based on these results, and under our experimental conditions, the peak could be conceivably assigned to the presence of the ions inside the DWCNTs, an assignment that is further supported by the lack of redox behavior of purified DWCNTs 

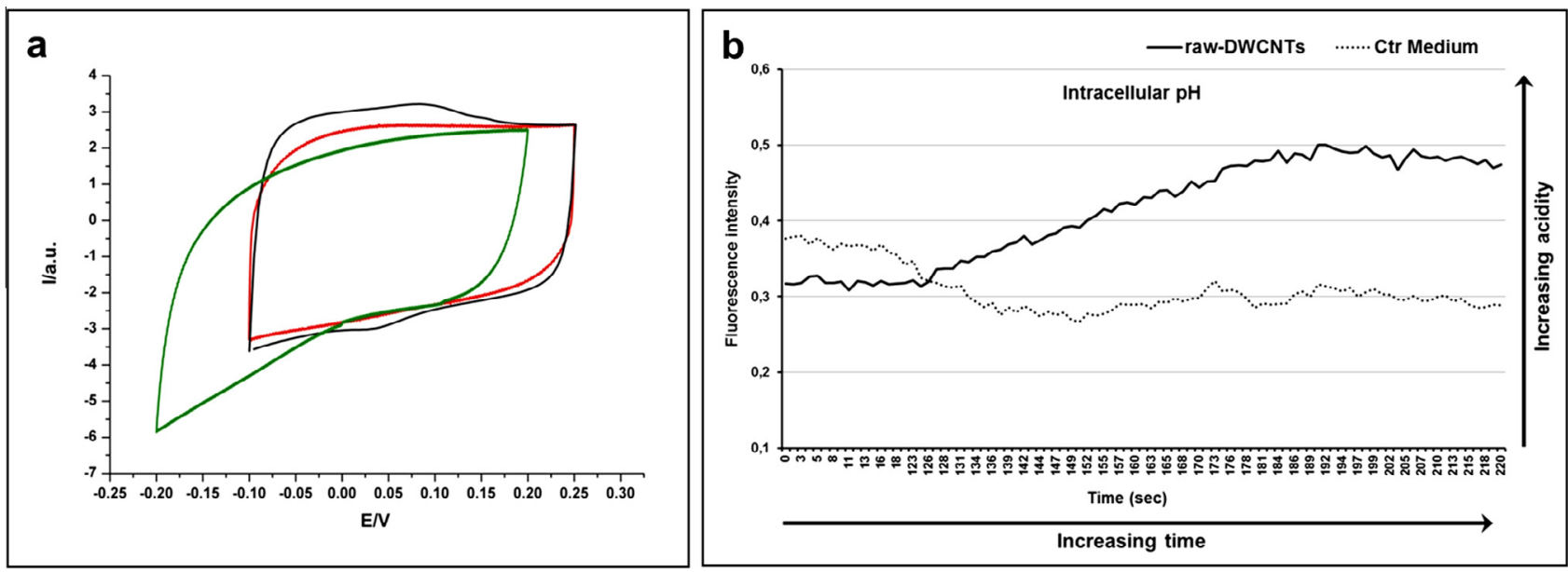

Fig. 4 - Effect on the intracellular pH of DHD/K12/Trb cells and electrochemical behavior of raw-DWCNTs. (a) Cyclic voltammetry of purified DWCNTs (red line), raw-DWCNTs (black line) and Co@C nanoparticles (green line). Scan rate $10 \mathrm{mV} \mathrm{s}-1$, potential are reported versus $\mathrm{Ag} / \mathrm{AgCl}$. (b) Changes of intracellular $\mathrm{pH}$ evaluated using the LysoSensor Green DND-189 probe, during the first $240 \mathrm{~s}$ after addition of raw-DWCNTs to cell culture medium. Fluorescence measurements were performed by CLSM as described in the Methods; results are the mean of all regions of interest (ROIs) analyzed in three separate experiments; control (Ctr Medium) consisted in cells after addition of culture medium alone.

and by the same lack of redox activity observed for Co@C particles (Fig. 4a), despite their high content of Co (Co\% $20.3 \pm 0.2)$, and the small but significant amount of $\mathrm{Fe}(\mathrm{Fe} \%$ $2.0 \pm 0.3$ ) (Fig. 1b).

In the working conditions, i.e., vs $\mathrm{Ag} / \mathrm{AgCl}(3 \mathrm{M} \mathrm{KCl})$, the reduction potentials of $\mathrm{Mo}^{+3}, \mathrm{Co}^{+2}, \mathrm{Fe}^{+2}$, and $\mathrm{Zn}^{+2}$ are $-0.40 \mathrm{~V},-0.48 \mathrm{~V},-0.64 \mathrm{~V}$, and $-0.98 \mathrm{~V}$. These values are at least half a Volt from the potential, $\sim 70 \mathrm{mV}$, observed. Part of the shift might be assigned to small charged clusters of few metal atoms, which are more easily reducible than the corresponding metal ion. However, because of its large value another mechanism must be in operation and needs to be identified. For a charged particle inside a metallic cylinder the electrostatic potential inside the tube can be obtained by solving the Poisson equation. Isolated charges inside the tube are unlikely to occur since the cautions will have a nearby counter-ion. A dipole of length $l$ and charges $\pm q$ can represent the remnant of the catalyst. The CNTs used in the present work are closed CNTs. Cobalt impurities, probably in the form of charged clusters, are entrapped in the carbon nanotubes and cannot leave. Their charge must be counterbalanced. Oxygen-derived moieties can reasonably provide electroneutrality. In practice a dipole is formed, polarize the metallic carbon nanotube and changes its redox potential (a sketch of the physical situation used in the calculations is added in the Supplementary Fig. S3). The dipole induces a charge on the surface of the tube and experiences an induced electrostatic potential that can be calculated by applying the Green function expansion method [27]. Different cases where the dipole features, or position, are modified were considered (Supplementary Fig. S3). If the dipole is located on the tube axis, the induced potential increases with the length of the dipole, until it reaches the maximum obtainable for two isolated charges. For a dipole length of $4 \AA$ made by two charges each twice the electron charge, the extra potential on the dipole is similar to that observed in the experimental shift of the reduction potential, $\sim 0.6 \mathrm{~V}$. As the dipole moves from the axis toward the sidewall, the potential increases. The alternative arrangement, where the dipole is perpendicular to the main axis generates lower induced potentials.

We investigated whether raw-DWCNTs were able to induce intracellular $\mathrm{pH}$ changes, as previously demonstrated for MWCNTs [10]; to this purpose, analysis of the intracellular $\mathrm{pH}$ was performed by using the acidotropic probe LysoSensor Green DND-189 [10] as described in Methods paragraph. Measurements showed that raw-DWCNTs induced an acidification of the intracellular compartment, due to the entry of $\mathrm{H}^{+}$ions into the cytoplasmic compartments, following the contact of CNTs with cell membranes thus affecting the $\mathrm{pH}$ homeostasis between intra- and extra-cellular microenvironments (Fig. 4b).

3.5. Assessment of Co@C interaction with rat colon adenocarcinoma cells and of intracellular ROS production

In addition, in order to verify whether the above described effects of raw-DWCNTs on adenocarcinoma cells could be attributed to Co particles, we evaluated the biological effects of Co@C and purified DWCNTs on the same cells, by exploring their ability to inhibit cell proliferation. The assessment of the MI, of the cell proliferation marker Ki67 and of the number of cells blocked in $\mathrm{G}_{2}$ phase revealed that neither Co@C particles nor purified DWCNTs induced any effects on the proliferation indexes (Fig. 5a and b). The potential to stimulate the ROS production in cells was examined by assessing the fluorescent measurement of intracellular oxidative stress. Intracellular ROS were determined by evaluating the oxidative conversion of $\mathrm{CM}-\mathrm{H}_{2} \mathrm{DCFDA}$ to the fluorescent product, after 

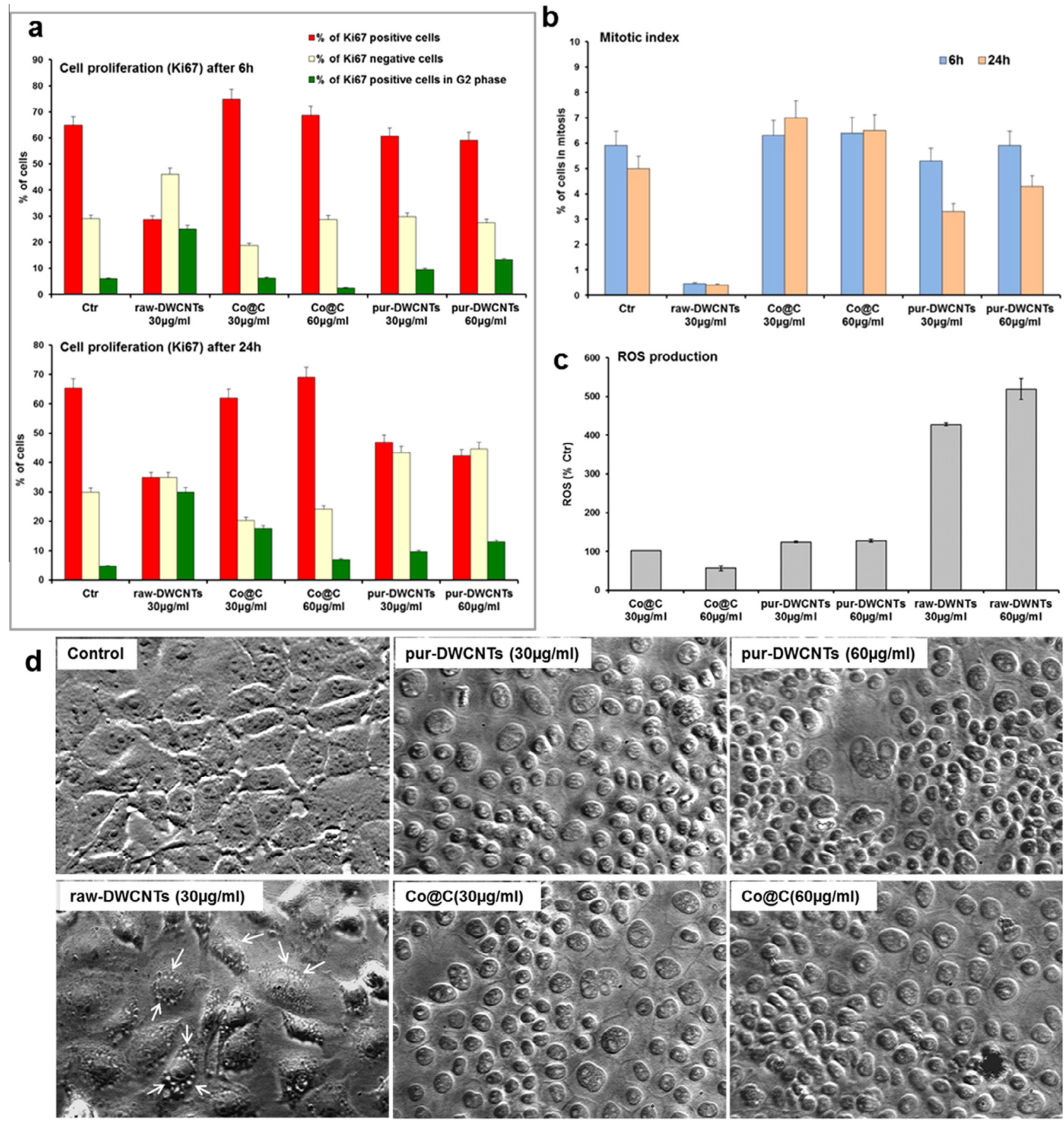

Fig. 5 - Comparative analyses of the effects of raw-DWCNTs, Co@C particles and purified DWCNTs on DHD/K12/trb cells. (a) Cell proliferation analyzed by immunofluorescent staining of Ki67; the percentage of cells in $\mathrm{G}_{2}$ phase was evaluated based on Ki67 nucleolar localization. (b) Mitotic index evaluation after $6 \mathrm{~h}$ and $24 \mathrm{~h}$ treatment. (c) Ros production determined by cytofluorimetric analysis using CM- $\mathrm{H}_{2} \mathrm{DCFDA}$ as fluorescent probe. (d) Cell morphology of DHD/K12/trb cells analyzed by phase contrast microscopy after $48 \mathrm{~h}$ treatment with raw-DWCNTs, Co@C particles or purified DWCNTs. (A color version of this figure can be viewed online.)

exposure to $30 \mu \mathrm{g}$ and $60 \mu \mathrm{g}$ of raw-DWCNTs, Co@C particles and purified DWCNTs for $1 \mathrm{~h}$, as described in Methods. The results showed that only raw-DWCNTs induced an early significant production of ROS in cells in a dose-dependent manner, as compared to Co@C particles and purified DWCNTs (Fig. 5c).
3.6. Assessment of raw-DWCNT ability to modulate autophagy

The morphological observation performed by phase contrast microscopy showed that, after $48 \mathrm{~h}$ treatment with $30 \mu \mathrm{g} / \mathrm{ml}$ of raw-DWCNTs, cells presented numerous cytoplasmic and 
perinuclear vacuoles (arrows in Fig. 5d), that were absent in untreated control as well as in cells treated with pyrolytic graphite particles (not shown). Conversely, the microscopic analysis showed that both Co@C nanoparticles and purified DWCNTs had no effects in inducing intracellular vacuolization (Fig. 5d).

Thus, the hypothesis that the raw-DWCNT capacity to inhibit tumor cell proliferation could occur by influencing the autophagic activity of DHD/K12/Trb cells was investigated. Autophagy was preliminary evaluated by analyzing the redistribution at the level of cytoplasmic vacuoles and lysosome-like structures of endogenous LC3. Cells, treated with raw-DWCNTs for 6, 24 and $48 \mathrm{~h}$, were subjected to LC3 immunofluorescent staining. As shown in Fig. 6a, after $48 \mathrm{~h}$ of treatment, the number of LC3 positive vacuoles and lysosome-like structures per autophagic cells, as well as the percentage of autophagic cells, was about 2-fold higher in raw-DWCNT treated cultures than in untreated control, but lower to those recorded in cultures in which autophagy was induced by starvation condition (growth in serum-free medium).

In order to confirm the effect on autophagic activity evidenced by confocal microscopy in our colon cancer cells, we performed the analysis of the LC3-I and LC3-II (nonlipidated and lipidated forms, respectively) expression by Western Blot (Fig. 6b). Lysosomal turnover of endogenous LC3-II was analyzed in all samples (control, DWCNTs and starvation) after 24 and $48 \mathrm{~h}$ of culture in absence and in presence of the two lysosomal protease inhibitors E64d and Pepsatin. Results reported in Fig. $6 \mathrm{~b}$, show that, after $24 \mathrm{~h}$ of culture

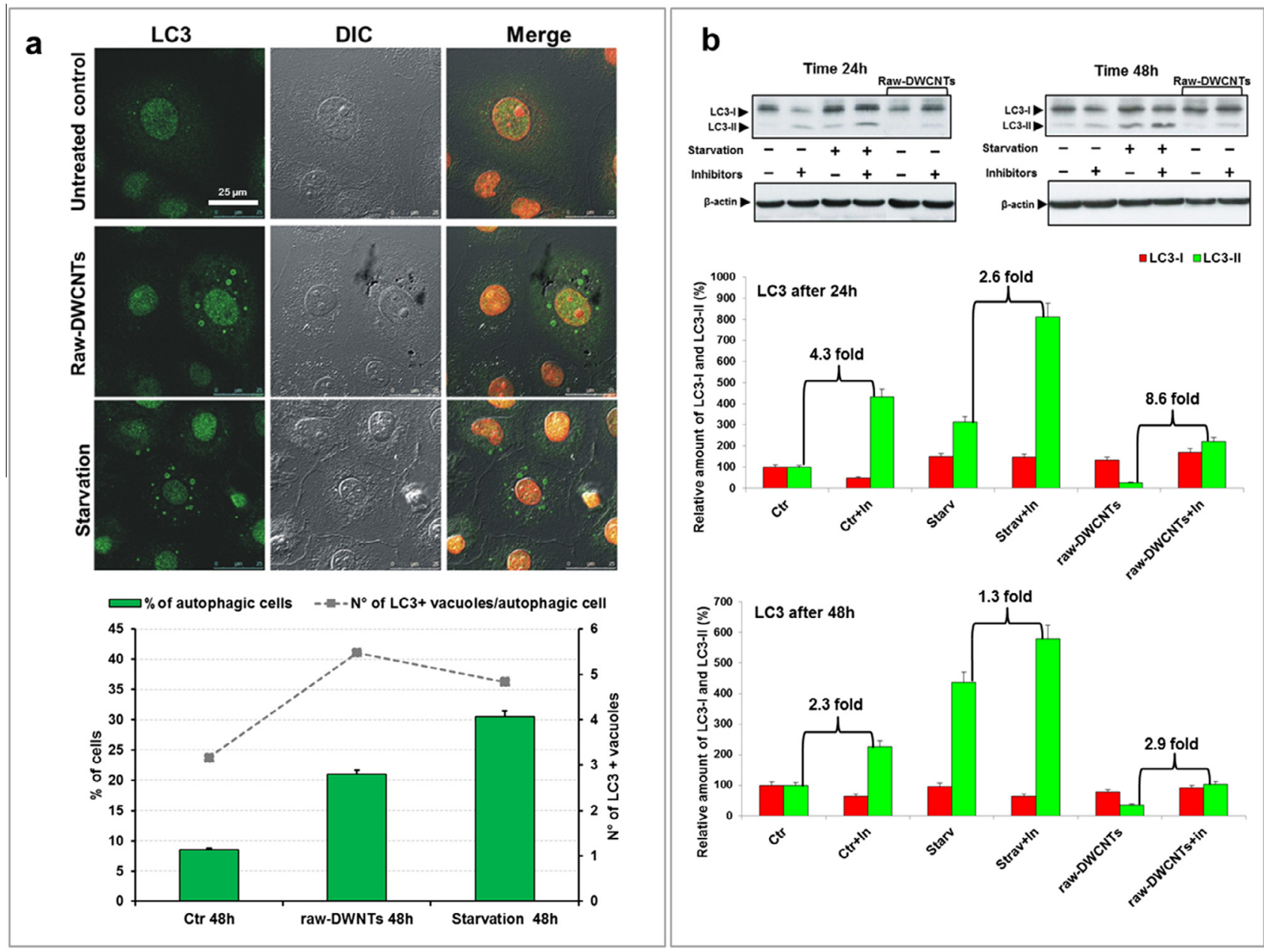

Fig. 6 - Induction of autophagic vacuoles in DHD/K12/trb cells by raw-DWCNTs. (a) Autophagy analysis performed by evaluating the expression and redistribution at cytoplasmic vacuoles of the autophagy membrane marker LC3 after $48 \mathrm{~h}$ treatment with raw-DWCNTs. Cells grown in starvation condition, were used as positive control of autophagy. Images (top) show the merging of differential interference contrast (DIC), LC3 immunofluorescent staining (green hue) and nuclei staining with PI (red hue). Quantitative assessment (bottom), was reported as percentage of LC3-positive cells (solid bar graph) and as number of LC3-stained vacuoles per positive cells (dotted line). (b) Western Blot analysis of the expression LC3-I and LC3-II (nonlipidated and lipidated forms, respectively). Lysosomal turnover of endogenous LC3-II was analyzed in all samples (control, DWCNTs and starvation) after 24 and $48 \mathrm{~h}$ of culture in absence and in presence of the two lysosomal protease inhibitors E64d and Pepsatin. Results from the densitometric analysis of LC3-I and LC3-II levels (bar graphs) were normalized to $\beta$-actin and were reported as percent $v$ s amounts in untreated controls. (A color version of this figure can be viewed online.) 
in absence of protease inhibitors, while endogenous LC3-II significantly increased during starvation-induced autophagy (3.14-fold higher us Ctr), raw-DWCNTs induced a decrease of the LC3 lipidated form, as compared to untreated control (3.9-fold lower us Ctr). Interestingly, when lysosomal turnover of endogenous LC3-II was inhibited by E64d and Pepsatin, LC3-II markedly accumulated in cells grown in serum-free medium (2.6-fold of increment us starvation without inhibitors), coherently with autophagy induction, but a much higher increase was recorded in raw-DWCNTs treated cultures (8.9-fold of increment us raw-DWCNTs without inhibitors).

\section{Discussion}

Based on our previous findings [10-11] on the effects of electro-conductive MWCNTs on "charge-sensitive" cell functions, we investigated whether another kind of metallic nanotubes, Double-Walled-Carbon-Nanotubes, could positively and selectively interact with tumor cells. We evaluated the biological effects of raw-DWCNTs on rat colon adenocarcinoma cells. In first instance, the effects of raw-DWCNTs on viability, proliferation and cell cycle of rat adenocarcinoma cells were investigated. A significant $(P=0.0022)$ reduction in the number of viable cells induced by raw-DWCNTs was observed. Moreover, the mitotic index evaluation and the assessment of Ki67 positivity demonstrated that raw-DWCNTs were able to significantly reduce the proliferation rate of colorectal cancer cells and to block the cell cycle in the $\mathrm{G}_{2} / \mathrm{M}$ phase, strongly suggesting that they selectively target cycling cells and spare uncycling non tumoral cells. Furthermore, raw-DWCNTs were not observed to induce cell apoptosis. No unambiguous results on the induction of apoptosis by CNTs have been reported. Single-Walled Carbon-Nanotubes (SWCNTs) were showed to exert genotoxic effect in renal epithelial cells, to induce growth arrest in $G_{1}$ phase, apoptosis and DNA damage [31-32]. CNTs were observed to affect the cell proliferation rate as well as the cell cycle in monocytic cells and to induce apoptosis in $\mathrm{T}$ lymphocytic cells [33-34]. MWNTs were reported to interact with microtubules of human cancer cells blocking mitosis and leading to cell death by apoptosis [35].

In order to deep the mechanisms by which raw-DWNTs inhibit cancer cell proliferation, we analyzed their influence on the Wnt/ $\beta$-catenin signaling pathway, which deregulation or constitutive activation has a key role in the initiation and progression of different forms of human cancer [30]. Even if, after raw-DWCNT treatment, we observed a nuclear export of the oncoprotein $\beta$-catenin and an increased expression of E-cadherin at the cell-cell junctions, suggestive of Wnt pathway reversion, we did not recorded an early significant effect on $\beta$-catenin, E-cadherin, $c$-Myc and Cyclin D1 genes, indicating that this kind of CNTs not primarily affects the Wnt signaling.

Thus, we investigated whether the inhibition of tumoral cell proliferation could occur through the stimulation of autophagy, the cellular catabolic process by which cytoplasmic target material is transported to lysosomes for degradation. Autophagy in mammalian systems occurs under basal conditions and can be stimulated by stresses like starvation, pathologies, or treatment with pharmacological agents. Dysfunction in the autophagy pathway is implicated in infectious diseases as well as in cancer and neuro-degeneration. The evaluation of autophagy was performed both by analyzing the redistribution at the level of cytoplasmic vacuoles and lysosome-like structures of endogenous LC3 by immunofluorescence and by monitoring LC3-I and LC3-II (nonlipidated and lipidated forms, respectively) by western blot. The percentage of autophagic cells, as well as the number of LC3 positive vacuoles per autophagic cells, was significantly higher in raw-DWCNT treated cells than in untreated control cells. The autophagic activity evidenced by confocal microscopy was not confirmed by the analysis of the LC3-I and LC3-II by Western Blot. Different explanations could account for these apparently contradictory results. First of all, quantification of autophagy by measuring LC3 by immunofluorescence can be more tedious, than monitoring LC3-II by western blot; however, the former may be more sensitive and quantitative [36], the numbers of LC3 positive puncta in the cytoplasm, may reflect only a snapshot of the numbers of autophagy-related structures (e.g., autophagosomes) in a cell, and not the autophagic flux [36]; LC3-II also associates with the membranes of non-autophagic structures. For example, some members of the $\gamma$-protocadherin family undergo clustering to form intracellular tubules that emanate from lysosomes. LC3-II is recruited to these tubules, that are not associated with autophagic vesicles [37]. Even if the molecular data on LC3 expression did not confirm the induction of autophagy by raw-DWCNTs, the results obtained strongly suggest that this kind of CNTs might influence the autophagic flux, increasing lysosomal turnover of endogenous LC3-II.

Several signaling pathways seem to regulate autophagy in mammalian cells. The tumor acidic microenvironment can significantly affect the activity of autophagy [38-43]. We observed that raw-DWCNTs induced an acidification of the intracellular compartment in rat tumor cells, due to the entry of $\mathrm{H}^{+}$ions into the cytoplasmic compartments. We hypothesized that the direct effect on the induction of intra cellular $\mathrm{pH}$ changes could be attributed to the cationic exchange ability of electro conductive DWCNTs and to the sorption of divalent ions on their surface $[11,12,14]$, due to the ability of CNTs to mediate electron transfer reactions with electro active species in solution. Cyclic Voltammetry performed on raw-DWCNTs showed a redox peak, attributable to metallic impurities left over from the catalyst used in the synthesis. Due to the limited release of Co into RPMI culture medium, as showed by the analysis of the release of Co ions from raw-DWCNTs into culture medium, we hypothesized that the peak could be assigned to the presence of Co ions inside the DWCNTs. Our hypothesis was further supported by the lack of redox behavior of purified DWCNTs and by the same lack of redox activity observed for Co@C particles, despite their high content of Co. To confirm the experimental results, we evaluated the biological effects of Co@C and purified DWCNTs on rat adenocarcinoma cells, exploring their ability to induce inhibition of cell proliferation and autophagy. No effects on the induction of proliferation indexes by Co@C and purified DWCNTs was observed, thus concurring with the absence of redox behavior in these particles. In addition, the autophagy analysis showed that both Co@C nanoparticles and purified DWCNTs had no effects on the generation of vacuoles/autophagic cells. Finally, given the redox capacity of 
raw-DWCNTs, we examined their potential to stimulate the production of ROS in cell cultures. Only raw-DWCNTs were shown to induce an early significant production of ROS in a dose-dependent manner, as compared to Co@C particles and purified DWCNTs. ROS control a wide range of cell signal-transduction pathways leading to cell survival, proliferation, and death and have recently begun to emerge as important signaling molecules that regulate autophagic activity [44,45]. Since autophagy is a well-known stressinduced cellular survival mechanism, stimuli that trigger ROS generation signaling pathways may in turn induce autophagy [46-49].

Here we show that redox active DWCNTs are able to inhibit cancer cell proliferation, likely through the induction of ROS generation and intracellular compartment acidification. The influence on the autophagic flux would be in accordance to the acidification of the intracellular compartment recorded after raw-DWCNT treatment.

In conclusion, our results give preliminary evidence suggesting that raw-DWCNTs are able to affect the autophagic machinery, thus influencing a pathway critical for cancer cell survival. Currently, autophagy is one of the latest targets investigated for a growing number of anticancer drugs [50], and circumstantial support exists for the concept that autophagy may act as a tumor-suppressor pathway. In general, there is a positive correlation between molecules that induce autophagy and tumor suppression, and between molecules that inhibit autophagy and tumor progression [51]. However, the role of autophagy in regulating cancer cell death or survival has not been fully elucidated yet. When cancer cells are subjected to unfavorable conditions, such as nutrient-deficient environment or treatment with anticancer drugs, autophagy is rapidly upregulated to function as a cytoprotective mechanism which enhances cancer cell survival, and may contribute to the resistance to anticancer therapies. It has also been shown that when cells with defects in apoptosis are subjected to metabolic stress, they activate autophagy to survive. Inhibition of autophagy triggers a necrotic pathway leading to cell death. In solid tumors, this necrosis is associated with inflammation, which creates a microenvironment favoring survival and increasing proliferation of a small population of damaged cells. The final effect of this process is that inhibition of autophagy leads to the enhancement of tumor growth $[52,53]$. From this point of view, the understanding of the mechanisms regulating the interplay between DWCNTs and cancer cells could lead to the exploitation of carbon nanotubes as next generation of nanomaterials possessing intrinsic properties of anticancer therapeutic tools. Further studies should be performed to elucidate the molecular mechanism/s underlying the observed phenomenon.

\section{Conflict of interest}

The authors report no conflict of interest.

\section{Source of support}

None.

\section{Acknowledgements}

The authors thank Dr. Francesca Wannenes, Ph.D, for contributing to some preliminary results.

\section{Appendix A. Supplementary data}

Supplementary data associated with this article can be found, in the online version, at http://dx.doi.org/10.1016/j.carbon. 2014.07.046.

\section{R E F E R E N C E S}

[1] Supronowicz PR, Ajayan PM, Ullmann KR, Arulanandam BP, Metzger DW, Bizios RJ. Novel current-conducting composite substrates for exposing osteoblasts to alternating current stimulation. J Biomed Mat Res A 2002;59:499-506.

[2] Mattson MP, Haddon RC, Rao AM. Molecular functionalization of carbon nanotubes and use as substrates for neuronal growth. J Mol Neurosci 2000;14:175-82.

[3] Hu H, Ni Y, Montana V, Haddon RC, Purpura V. Chemically functionalized carbon nanotubes as substrates for neuronal growth. Nano Lett 2004;4:507-11.

[4] Hu H, Ni YC, Mandal SK, Montana V, Zhao N, Haddon RC, et al. Polyethyleneimine functionalized single-walled carbon nanotubes as a substrate for neuronal growth. J Phys Chem B 2005;109:4285-9.

[5] McKenzie JL, Waid MC, Shi R, Webster TJ. Decreased functions of astrocytes on carbon nanofiber materials. Biomaterials 2004;25:1309-17.

[6] Lovat V, Pantarotto D, Lagostena L, Cacciari B, Grandolfo M, Righi M, et al. Carbon nanotube substrates boost neuronal electrical signaling. Nano Lett 2005;5:1107-10.

[7] Keefer EW, Botterman BR, Romero MI, Rossi AF, Gross GW. Carbon nanotube coating improves neuronal recordings. Nat Nanotechnol 2008;3:434-9.

[8] Mazzatenta A, Giugliano M, Campidelli S, Gambazzi L, Businaro L, Markram H, et al. Interfacing neurons with carbon nanotubes: electrical signal transfer and synaptic stimulation in cultured brain circuits. J Neurosci 2007;27:6931-6.

[9] Fabbro A, Cellot G, Prato M, Ballerini L. Interfacing neurons with carbon nanotubes: (re)engineering neuronal signaling. Prog Brain Res 2011;194:241-52.

[10] Fiorito S, Monthioux M, Psaila R, Pierimarchi P, Zonfrillo M, D'Emilia E, et al. Evidence for electro-chemical interactions between multi-walled carbon nanotubes and human macrophages. Carbon 2009;47:2789-809.

[11] Serafino A, Togna AR, Togna GI, Lisi A, Ledda M, Grimaldi S, et al. Highly electroconductive multiwalled carbon nanotubes as potentially useful tools for modulating calcium balancing in biological environments. Nanomed: Nanotechnol Biol Med 2012;8:299-307.

[12] Pumera M, Iwai H. Multicomponent metallic impurities and their influence upon the electrochemistry of carbon nanotubes. J Phys Chem 2009;113:4401-5.

[13] Koyama S, Kim YA, Hayashi T, Takeuchi K, Fujii C, Kuroiwa N, et al. In vivo immunological toxicity in mice of carbon nanotubes with impurities. Carbon 2009;47:1365-72.

[14] Nugent JM, Santhanam KSV, Rubio A, Ajayan PM. Fast electron transfer kinetics on multiwalled carbon nanotube microbundle electrodes. Nano Lett 2001;1:87-91. 
[15] Wang J, Li M, Shi Z, Li N, Gu Z. Direct electrochemistry of cytochrome $\mathrm{c}$ at a glassy carbon electrode modified with single-wall carbon nanotubes. Anal Chem 2002;74:1993-7.

[16] Musameh M, Wang J, Merkoci A, Yuehe L. Low potential stable NADH detection at carbon-nanotube-modified glassy carbon electrodes. Electrochem Commun 2002;4:743-6.

[17] Wang J, Li M, Shi Z, Li N, Gu Z. Electrocatalytic oxidation of norepinephrine at a glassy carbon electrode modified with single wall carbon nanotubes. Electroanalysis 2002;14:225-30.

[18] Wang Z, Liu J, Liang Q, Wang YM, Luo G. Carbon nanotubemodified electrodes for the simultaneous determination of dopamine and ascorbic acid. Analyst 2002;127:653-8.

[19] Stuart EJE, Pumera M. Electrochemistry of a whole group of compounds affected by metallic impurities within carbon nanotubes. J Phys Chem 2010;114(49):21296-8.

[20] Ambrosi A, Pumera M. Regulatory peptides are susceptible to oxidation by metallic impurities within carbon nanotubes. Chemistry 2010;16:1786-92.

[21] Guo L, Morris DG, Liu X, Vaslet C, Hurt RH, Kane AB. Iron bioavailability and redox activity in diverse carbon nanotube samples. Chem Mater 2007;19:3472-8.

[22] Lukanov P, Anuganti VK, Krupskaya Y, Galibert AM, Soula B, Tilmaciu C, et al. CCVD synthesis of carbon-encapsulated cobalt nanoparticles for biomedical applications. Adv Funct Mater 2011;21:3583-8.

[23] Flahaut E, Bacsa R, Peigney A, Laurent Ch. Gram-scale CCVD synthesis of double-walled carbon nanotubes. Chem Commun 2003;21(12):1442-3.

[24] Kill IR. Localisation of the Ki-67 antigen within the nucleolus. Evidence for a fibrillarin-deficient region of the dense fibrillar component. J Cell Sci 1996;109:1253-63.

[25] Livak KJ, Schmittgen TD. Analysis of relative gene expression data using real-time quantitative PCR and the 2(-Delta Delta C(T)) method. Methods 2001;25(4):402-8.

[26] Firestone RB, Baglin CM, Chu SYF. Table of isotopes. 8th ed. Wiley-Interscience; 1999 [1999 Update on CD-ROM].

[27] Jackson JD. Classical electrodynamics. 2nd ed. New York: John Wiley and Sons; 1975. 116-118.

[28] Seichepine F, Salomon S, Collet M, Guillon S, Nicu L, Larrieu $\mathrm{G}$, et al. A combination of capillary and dielectrophoresisdriven assembly methods for wafer scale integration of carbon-nanotube-based nanocarpets. Nanotechnology 2012;23:095303.

[29] Osswald S, Flahaut E, Ye H, Gogotsi Y. Elimination of D-band in Raman spectra of double-wall-carbon nanotube by oxidation. Chem Phys Lett 2005;402:422-7.

[30] Miller JR, Hocking AM, Brown JD, Moon RT. Mechanism and function of signal transduction by the Wnt/beta-catenin and Wnt/Ca2+ pathways. Oncogene 1999;18:7860-72.

[31] Nam CW, Kang SJ, Kang YK, Mi-Kyoung Kwak MK. Cell growth inhibition and apoptosis by SDS-solubilized singlewalled carbon nanotubes in normal rat kidney epithelial cells. Arch Pharm Res 2011;34:661-9.

[32] Cui D, Tian F, Ozkan CS, Wang M, Huajian Gao H. Effect of single wall carbon nanotubes on human HEK293 cells. Toxicol Lett 2005;155:73-85.

[33] De Nicola M, Gattia DM, Bellucci S, De Bellis G, Micciulla F, Pastore R, et al. Effect of different carbon nanotubes on cell viability and proliferation. J Phys Cond Matter 2007;19:395013 (7pp).

[34] Bottini M, Bruckner S, Nika K, Bottini N, Bellucci S, Magrini A, et al. Multi-walled carbon nanotubes induce T lymphocyte apoptosis. Toxicol Lett 2006;160:121-6.

[35] Rodriguez-Fernandez L, Valiente R, Gonzalez J, Villegas JC, Fanarraga ML. Multiwalled carbon nanotubes display microtubule biomimetic properties in vivo, enhancing microtubule assembly and stabilization. ACS Nano 2012;6:6614-25.

[36] Klionsky DJ, Abdalla FC, Abeliovich H, Abraham RT, AcevedoArozena A, Adeli K, et al. Guidelines for the use and interpretation of assays for monitoring autophagy. Autophagy 2012;8(4):445-544.

[37] Hanson HH, Kang S, Fernández-Monreal M, Oung T, Yildirim $\mathrm{M}$, Lee R, et al. LC3-dependent intracellular membrane tubules induced by gamma-protocadherins A3 and B2: a role for intraluminal interactions. J Biol Chem 2010;285:20982-92.

[38] Gatenby RA, Gillies RJ. Why do cancers have high aerobic glycolysis? Nat Rev Cancer 2004;4:891-9.

[39] Chiche J, Brahimi-Horn MC, Pouyssegur J. Tumour hypoxia induces a metabolic shift causing acidosis: a common feature in cancer. J Cell Mol Med 2010;14:771-94.

[40] Huber V, De Milito A, Harguindey S, Reshkin SJ, Wahl ML, Rauch C, et al. Proton dynamics in cancer. J Transl Med 2010;15:8-57.

[41] Gatenby RA, Gillies RJ. A microenvironmental model of carcinogenesis. Nat Rev Cancer 2008;8:56-61.

[42] Rofstad EK, Mathiesen B, Kindem K, Galappathi K. Acidic extracellular $\mathrm{pH}$ promotes experimental metastasis of human melanoma cells in athymic nude mice. Cancer Res 2006;66:6699-707.

[43] Teng X, Hang S, Ganapathy S, Yuan ZM. Modulation of autophagic activity by extracellular pH. Autophagy 2011;7:1316-22.

[44] Valko M, Leibfritz D, Moncol J, Cronin MT, Mazur M, Telser J. Free radicals and antioxidants in normal physiological functions and human disease. Int J Biochem Cell Biol 2007;39:44-84.

[45] Scherz-Shouval R, Shvets E, Fass E, Shorer H, Gil L, Elazar Z. Reactive oxygen species are essential for autophagy and specifically regulate the activity of Atg4. EMBO J 2007;26:1749-60.

[46] Huang J, Lam GY, Brumell JH. Autophagy signaling through reactive oxygen species. Antioxid Redox Signal 2011;14:2215-31.

[47] Chen Y, Azad MB, Gibson SB. Superoxide is the major reactive oxygen species regulating autophagy. Cell Death Differ 2009;16:1040-52.

[48] Chen Y, McMillan-Ward E, Kong J, Israels SJ, Gibson SB. Oxidative stress induces autophagic cell death independent of apoptosis in transformed and cancer cells. Cell Death Differ 2008;15:171-82.

[49] Wong CH, Iskandar KB, Yadav SK, Hirpara JL, Loh T, Pervaiz S. Simultaneous induction of non-canonical autophagy and apoptosis in cancer cells by ROS-dependent ERK and JNK activation. PLoS One 2010;5(4):e9996.

[50] Zhang H, Kong X, Kang J, Su J, Li Y, Zhong J, et al. Oxidative stress induces parallel autophagy and mitochondria dysfunction in human glioma U251 cells. Toxicol Sci 2009;110:376-88.

[51] Ravikumar B, Sarkar S, Davies JE, Futter M, Garcia-Arencibia M, Green-Thompson ZW, et al. Regulation of mammalian autophagy in physiology and pathophysiology. Physiol Rev 2010;90:1383-435.

[52] Degenhardt K, Mathew R, Beaudoin B, Bray K, Anderson D, Chen $\mathrm{G}$, et al. Autophagy promotes tumor cell survival and restricts necrosis, inflammation, and tumorigenesis. Cancer Cell 2006;10:51-64.

[53] Comes F, Matrone A, Lastella P, Nico B, Susca FC, Bagnulo R, et al. A novel cell type-specific role of p38alpha in the control of autophagy and cell death in colorectal cancer cells. Cell Death Differ 2007;14:693-702. 